\title{
The Additive Effects of Hyaluronidase in Subacromial Bursa Injections Administered to Patients with Peri-Articular Shoulder Disorder
}

\author{
Seung Deuk Byun, M.D., Dong Hwi Park, M.D., Yong Ho Hong, M.D., Zee Ihn Lee, M.D.
}

Department of Rehabilitation Medicine, Dae-gu Fatima Hospital, Daegu 701-600, Korea

\begin{abstract}
Objective To evaluate the additive effects of hyaluronidase combined with steroids in patients with peri-articular shoulder disorder.

Method Thirty patients with peri-articular shoulder disorder were given subacromial bursa injections once a week for three consecutive weeks. Fifteen patients (Group A) underwent subacromial bursa injections with hyaluronidase 1,500 IU, triamcinolone $40 \mathrm{mg}$ and $0.5 \%$ lidocaine (total $6 \mathrm{ml}$ ). Another fifteen patients (Group B) underwent the same injections with triamcinolone $40 \mathrm{mg}$ and $0.5 \%$ lidocaine (total $6 \mathrm{ml}$ ). We examined the active range of motion (AROM) in the shoulder, used a visual analogue scale (VAS) for measurement, and administered a shoulder disability questionnaire (SDQ) at the commencement of the study and then every week until one week after the third injection.

Results There were no significant difference between group A and B before the injections took place ( $p>0.05)$. Statistically significant improvement was seen in the VAS, SDQ, and AROM of flexion, abduction, internal rotation at one week after the first and second injections compared with the parameters measured at previous visits in both groups $(\mathrm{p}<0.05)$, except the SDQ between one week after the first and second injections in group B ( $>0.05)$. Improvement in all parameters measured at one week after the third injection compared with the measurement values at one week after the second injection were not statistically significant in both groups ( $>0.05)$. However, group A (the hyaluronidase group) showed significantly greater improvements than group B in terms of their SDQ and AROM of internal rotation scores one week after the three injections had taken place $(\mathrm{p}<0.05)$.

Conclusion Peri-articular shoulder disorder patients who underwent subacromial bursa injections using hyaluronidase and steroids showed greater functional improvements than those who were given only steroid injections.
\end{abstract}

Key Words Hyaluronidase, Steroid, Subacromial bursa, Shoulder

Received June 22, 2011; Accepted October 18, 2011

Corresponding author: Dong Hwi Park

Department of Rehabilitation Medicine, Dae-gu Fatima Hospital, 576-31, Shinam-dong, Dong-gu, Daegu 701-600, Korea

Tel: +82-53-940-7824, Fax: +82-53-954-7417, E-mail: Bdome@hanmail.net

(c) This is an open-access article distributed under the terms of the Creative Commons Attribution Non-Commercial License (http://creativecommons. org/licenses/by-nc/3.0) which permits unrestricted noncommercial use, distribution, and reproduction in any medium, provided the original work is properly cited.

Copyright () 2012 by Korean Academy of Rehabilitation Medicine 


\section{INTRODUCTION}

Peri-articular shoulder disorder refers to a range of diseases, including subacromial-subdeltioid bursitis, calcific tendinitis and rotator cuff tendinopathy or tear. It typically causes shoulder pain and a limitation in terms of range-of-motion (ROM) ${ }^{1,2}$ A subacromial bursa injection is commonly used to relieve pain and to improve joint function in patients with periarticular shoulder disorder, and an injection of steroids and lidocaine is the most widely used. ${ }^{2-5}$ Yoon et al. ${ }^{2}$ suggested that, compared to a group of patients with peri-articular shoulder disorder who were administered with low dose steroids, the high dose group showed significant improvement in pain control, shoulder ROM and shoulder function. However, the higher dose group did also experience greater degeneration changes and more adverse events in metabolism and endocrine system function. ${ }^{2,6}$ There is some research related to the substitution of steroids with hyaluronic acid or combining them with adjuvants, but arguments about the effect of this still remain. ${ }^{7-9}$ It was shown that compared to steroid monotherapy, a combination of hyaluronidase and steroids, when injected into scar tissue, the nerve root, or injected intraspinally in patients with tuberculous arachnoiditis or with failed back surgery syndrome, achieved better treatment results. ${ }^{10-13}$ Seo et al. ${ }^{13}$ who specifically studied the shoulder joint, injected hyaluronidase and steroids into the articular cavity in patients with adhesive capsulitis and reported that there were significant improvements in pain relief and ROM, when compared to steroid monotherapy. However, there has been no research addressing subacromial bursa injections of hyaluronidase and steroids in patients with peri-articular shoulder disorder. This study therefore conducted subacromial bursa injections of steroids and hyaluronidase, a combination which is known to increase the local anesthetic absorption rate by modifying the permeability of the connective tissue, when compared with steroid monotherapy. We then, examined whether this combination therapy has further effects in the treatment of patients with peri-articular shoulder disorder.

\section{MATERIALS AND METHODS}

\section{Subjects}

Our study group comprised of patients who complained of shoulder pain and who came to our rehabilitation center from January to June 2011. The inclusion criteria were patients (1) who had a painful arc with Hawkin's sign or Neer's impringement sign; (2) who showed full or partial thickness rotator cuff tear or subacromial/ subdeltoid bursitis in ultrasonographic testing, with definite lesions in the rotator cuff; and (3) who had limitations in terms of their active ROM with stiffness, but not to the extent that they met the exclusion criteria of having adhesive capsulitis. This condition is diagnosed when the patient has normal radiographic findings and when the active and passive elevation of arm are measured as being less than 100 degrees when the patient raises his arms over his head to the maximum possible extent; and, when the passive external rotation of the glenohumeral joint, which is measured while the examiner holds the patient's wrist and twists his elbow up to 90 degrees, is decreased by $50 \%$ or more compared to the less affected side. Other excluded patients were those who have had previous shoulder surgery; who have already had injections of steroids or hyaluronic acid for the current condition; who suffered from hemiplegic shoulder pain syndrome; and, who showed a suspected fracture in the radiologic findings. The selected eligible patients were randomly placed into A and B groups.

\section{Subacromial bursa injections}

We conducted physical examination and assessment of patients' shoulder pain and function. Specifically, we used ultrasound to examine lesions. We asked the patient to move the applicable arm for internal rotation and for hyperextension of the arm at a sitting posture placing the lower arm on the back. Then, we disinfected the area to be injected and performed subacromial bursa injections under ultrasonographic guidance. We injected a total of three times at one week intervals in both groups. The A group received $40 \mathrm{mg}(1 \mathrm{ml})$ of triamcinolone acetonide (Dong Kwang Pharm., Seoul, Korea) and $3 \mathrm{ml}$ of $1 \%$ lidocaine with $1 \mathrm{ml}$ of hyaluronidase $\mathrm{H}$-lase ${ }^{\circledR}$ (Kuhnil Pharmaceutical, Seoul, Korea) and $1 \mathrm{ml}$ of normal saline. The B group received $40 \mathrm{mg}(1 \mathrm{ml})$ of triamcinolone acetonide and $3 \mathrm{ml}$ of $1 \%$ lidocaine with $2 \mathrm{ml}$ of normal 
saline; there was a total of $6 \mathrm{ml}$ of injection material with an $\mathbf{0 . 5 \%}$ lidocaine level for each group. One week prior to injection, patients were asked to suspend their administration of painkillers or anti-inflammatory drugs. They were taught to perform scapular stabilizer strengthening exercises and range of motion exercises at home after the injections; we continuously trained and recommended such exercises at every follow-up. There was no other physical therapy or drug treatment involved in this study.

\section{Evaluation of injection effect}

We evaluated subjects four times: once before their first injection, and one week after their first, second, and third injections. These evaluations were conducted by one examiner. This examiner asked patients to report the mean value of their degree of pain for the 24 hours prior to injection and measured with a visual analog scale (from zero to 10 points). He then measured the active ROM of patients' shoulder joints and did not limit scapula motion. For shoulder flexion and abduction measurement, he asked the patient to extend their elbow joints while sitting down and then measured the ROM of the upper limb in the sagittal and coronal planes. To assess internal and external rotation, the examiner measured the range of internal and external rotation that the patients had while in a sitting posture and externally rotating their shoulders at 90 degrees. The normal range of shoulder flexion and abduction was 180 degrees for both; for internal and external rotation, it was 90 degrees. To evaluate the shoulder function of our patients, we used a shoulder disability questionnaire (SDQ). This is a tool that can assess the degree of shoulder disorder that a patient reports. SDQ's validity and reliability have been verified. It is composed of 22 self-reporting items, with results scores ranging from zero (no disability) to 22 (greatest possible disability). ${ }^{14}$

\section{Statistical analysis}

We compared age, gender and lesion between two groups by using Chi-square and independent t-tests. We also compared measures before patients' first injection and one week after their first, second, and third injections in both the combination and monotherapy groups. We used Wilcoxon signed rank testing to compare the two groups at each timepoint. SPSS 12.0 was used, at the 0.05 level of significance.

\section{RESULTS}

\section{Characteristics and ultrasonic findings of subjects}

The study examined 30 people; 15 patients in each

Table 1. General Characteristics of Subjects

\begin{tabular}{lccc}
\hline & Group A & Group B & Total \\
\hline Number of subject & 15 & 15 & 30 \\
Sex (male/female) & $7 / 8$ & $6 / 9$ & $13 / 17$ \\
\hline Age (years) & $53.8 \pm 9.8$ & $55.4 \pm 10.0$ & $54.6 \pm 9.9$ \\
Shoulder affected, n (\%) & & & \\
$\quad$ Dominant & $10(66.7 \%)$ & $10(66.7 \%)$ & $20(66.7 \%)$ \\
Non-dominant & $5(33.3 \%)$ & $5(33.3 \%)$ & $10(33.3 \%)$ \\
VAS & $6.4 \pm 1.7$ & $6.8 \pm 1.9$ & $6.6 \pm 1.8$ \\
\hline SDQ & $8.3 \pm 4.9$ & $4.9 \pm 3.7$ & $6.6 \pm 4.6$ \\
Range of motion (degree) & & $167.1 \pm 16.8$ & $168.2 \pm 12.2$ \\
$\quad$ Flexion & $165.0 \pm 8.6$ & $165.0 \pm 22.8$ & $162.1 \pm 23.8$ \\
Abduction & $155.7 \pm 25.0$ & $62.9 \pm 11.4$ & $57.7 \pm 13.3$ \\
\hline IR & $52.5 \pm 13.4$ & $84.3 \pm 10.9$ & $84.6 \pm 11.0$ \\
\hline ER & $85.0 \pm 11.6$ & & \\
\hline
\end{tabular}

Values are mean \pm standard deviation

Group A: Patients injected with 0.5\% lidocaine $4 \mathrm{ml}+$ triamcinolone $40 \mathrm{mg}+$ hyaluronidase $1 \mathrm{ml}$, Group B: Patients injected with $0.5 \%$ lidocaine $5 \mathrm{ml}+$ triamcinolone $40 \mathrm{mg}$, VAS: Visual analogue scale, SDQ: Shoulder disability questionnaire, IR: Internal rotation, ER: External rotation

${ }^{*} \mathrm{p}<0.05$ between Group A and Group B 
group. There was no significant difference in patients' age, gender and lesion or in individual measures between the two groups before injections (Table 1). In addition, there was no significant difference in our pre-injection ultrasonographic findings (Table 2).

\section{Changes in visual analog scale (VAS) of pain}

In both groups, a significant improvement in VAS was observed after the first injection. Both groups also showed significant improvement after the second injection, as compared to their status after the first injection. There was no statistically significant improvement after the third injection compared to the point after the second injection (Table 3). However,

Table 2. Ultrasonographic Diagnosis before Injection

\begin{tabular}{ccc}
\hline Findings & $\begin{array}{c}\text { Group A } \\
(\mathbf{n = 1 5 )}\end{array}$ & $\begin{array}{c}\text { Group B } \\
(\mathbf{n}=15)\end{array}$ \\
\hline RC partial-tear & 6 & 6 \\
RC full-thickness tear & 4 & 4 \\
SA-SD bursitis & 5 & 5 \\
\hline
\end{tabular}

Values: number of cases

RC: Rotator cuff, SA-SD: Subacromial-subdeltoid the results after third injection showed that there were significant improvement in both groups, compared to pre-injection results, but that there was no statistically significant difference in improvement between the two groups (Table 4).

Table 4. Changes in Measurement Values for Group A and B

\begin{tabular}{lcc}
\hline & Group A & Group B \\
\hline VAS & $6.1 \pm 1.7$ & $4.4 \pm 2.4$ \\
SDQ & $7.7 \pm 4.7^{*}$ & $1.3 \pm 1.3$ \\
\hline Range of motion (degree) & & \\
$\quad$ Flexion & $12.1 \pm 7.0$ & $10.0 \pm 13.0$ \\
Abduction & $22.1 \pm 22.9$ & $11.4 \pm 16.1$ \\
\hline IR & $36.4 \pm 12.0^{*}$ & $18.6 \pm 7.7$ \\
\hline ER & $7.3 \pm 11.0$ & $5.0 \pm 9.4$ \\
\hline
\end{tabular}

Values are mean \pm standard deviation

Group A: Patients injected with $0.5 \%$ lidocaine 4 $\mathrm{ml}+$ triamcinolone $40 \mathrm{mg}$ +hyaluronidase $1 \mathrm{ml}(1,500$ IU), Group B: Patients injected with $0.5 \%$ lidocaine 5 $\mathrm{ml}+$ triamcinolone $40 \mathrm{mg}$, VAS: Visual analogue scale, SDQ: Shoulder disability questionnaire, IR: Internal rotation, ER: External rotation ${ }^{*} \mathrm{p}<0.05$

Table 3. Summary of Treatment Effects for both Group A and B

\begin{tabular}{|c|c|c|c|c|c|}
\hline & Group & Pre-injection & $\begin{array}{c}1 \text { week after } 1^{\text {st }} \\
\text { injection }\end{array}$ & $\begin{array}{c}1 \text { week after } 2^{\text {nd }} \\
\text { injection }\end{array}$ & $\begin{array}{c}1 \text { week after } 3^{\text {rd }} \\
\text { injection }\end{array}$ \\
\hline \multirow[t]{2}{*}{ VAS } & A & $6.4 \pm 1.7$ & $2.3 \pm 1.2^{\dagger}$ & $0.5 \pm 0.7^{\ddagger}$ & $0.3 \pm 0.5^{*}$ \\
\hline & B & $6.8 \pm 1.9$ & $3.5 \pm 1.7^{\dagger}$ & $2.4 \pm 1.5^{\dagger}$ & $2.4 \pm 1.8^{*}$ \\
\hline \multirow[t]{2}{*}{ SDQ } & A & $8.8 \pm 8.5$ & $3.3 \pm 3.5^{\dagger}$ & $1.2 \pm 2.8^{\ddagger}$ & $0.6 \pm 1.5^{*}$ \\
\hline & B & $4.9 \pm 3.7$ & $3.8 \pm 4.3^{\dagger}$ & $3.8 \pm 4.4$ & $3.6 \pm 4.2^{*}$ \\
\hline \multicolumn{6}{|l|}{ ROM (degree) } \\
\hline \multirow[t]{2}{*}{ Flexion } & A & $165.0 \pm 8.5$ & $172.1 \pm 9.8^{\dagger}$ & $177.1 \pm 6.1^{\ddagger}$ & $177.1 \pm 6.1^{*}$ \\
\hline & B & $167.1 \pm 17.0$ & $175.0 \pm 9.4^{\dagger}$ & $177.9 \pm 4.3$ & $177.1 \pm 6.1^{*}$ \\
\hline \multirow[t]{2}{*}{ Abduction } & A & $155.7 \pm 25.0$ & $168.6 \pm 18.8^{\dagger}$ & $176.8 \pm 6.1^{\ddagger}$ & $177.8 \pm 5.8^{*}$ \\
\hline & B & $165.0 \pm 22.8$ & $172.1 \pm 10.5^{\dagger}$ & $176.4 \pm 5.0^{\ddagger}$ & $176.4 \pm 8.4^{*}$ \\
\hline \multirow[t]{2}{*}{ Internal rotation } & A & $52.5 \pm 13.4$ & $77.9 \pm 11.2^{\dagger}$ & $88.6 \pm 3.6^{\ddagger}$ & $89.3 \pm 2.7^{*}$ \\
\hline & B & $62.9 \pm 11.4$ & $74.3 \pm 10.2^{\dagger}$ & $81.4 \pm 10.3$ & $85.7 \pm 8.5^{*}$ \\
\hline \multirow[t]{2}{*}{ External rotation } & A & $85.0 \pm 11.6$ & $88.6 \pm 3.6$ & $90.0 \pm 0.0$ & $89.6 \pm 1.3$ \\
\hline & B & $84.3 \pm 13.3$ & $85.7 \pm 11.0$ & $89.3 \pm 2.7$ & $89.3 \pm 2.7$ \\
\hline
\end{tabular}

Values: mean \pm standard deviation

Group A: Patients who were injected with $0.5 \%$ lidocaine $4 \mathrm{ml}$ +triamcinolone $40 \mathrm{mg}$ +hyaluronidase $1 \mathrm{ml}(1,500 \mathrm{IU})$, Group B: Patients who were injected with $0.5 \%$ lidocaine $5 \mathrm{ml}+$ triamcinolone $40 \mathrm{mg}$, VAS: Visual analogue scale, SDQ: Shoulder disability questionnaire

${ }^{*} \mathrm{p}<0.05$ pre-injection vs 1 weeks after $3^{\text {rd }}$ injection, ${ }^{\dagger} \mathrm{p}<0.05$ pre-injection vs 1 week after $1^{\text {st }}$ injection, ${ }^{\dagger} \mathrm{p}<0.051$ week after $1^{\text {st }}$ injection vs 1 week after $2^{\text {nd }}$ injection, ${ }^{\$} \mathrm{p}<0.051$ week after $2^{\text {nd }}$ injection vs 1 week after $3^{\text {rd }}$ injection 


\section{Changes in SDO}

In both groups, significant improvement in SDQ scores after first injection was observed. After the second injection, the A group showed statistically significantly improvement, but the B group did not. After third injection, there was no statistically significant improvement in either groups, compared to after the second injection (Table 3). However, the results after the third injection were significantly improved compared to pre-injection results for both groups, more so for group A than group B (Table 4).

\section{Changes in the active ROM}

Both groups showed statistically significant improvements in terms of flexion and internal rotation after the first injection, compared to their pre-injection results. Abduction was significantly improved only in the A group after the first injection. Both groups presented significant improvements in abduction after the second injection compared to their status after the first one; however, only the A group showed significantly improved in flexion. After the third injection, there was no statistically significant difference between the two groups, relative to their status after the second injection.

When comparing post-third injection results with pre-injection results, both groups showed statistically significant improvements in their flexion, abduction and internal rotation (Table 3 ). The A group showed better results in terms of their flexion, abduction and internal rotation after the third injection compared to their results before treatment. The degree of improvement in internal rotation was more statistically significant in the A group than it was in the B group (Table 4).

\section{DISCUSSION}

Subacromial bursa steroid injections are commonly repeated in patients with peri-articular shoulder disorder; however, there have been multiple debates about the appropriate number of injections, intervals and the correct dosage to be used. ${ }^{15-17}$ To examine appropriate doses of steroid, Yoon et al. ${ }^{2}$ conducted 1 subacromial bursa injection using $10 \mathrm{mg}$ and $40 \mathrm{mg}$ of triamcinolone and observed the results after 1, 3 and 6 weeks. This work found no difference in efficacy between the 1- and 3-week results; however, it reported significant improvements in pain, ROM and function when using $40 \mathrm{mg}$ compared to $10 \mathrm{mg}$. To examine the optimum number of injections, Tillander et al. ${ }^{16}$ performed subacromial bursa injections using saline and triamcinolone, injecting these into healthy mice a total of eight times (three times at oneweek intervals and five times at two-week intervals) and examined histologic alterations in rotator cuff activity. They reported that after three injections of triamcinolone, there was no histological change in rotator cuff activity, but that there was fragmentation of collagen, necrosis, and local inflammation after eight repeated injections. In addition, Byun et al. ${ }^{6}$ studied the effect of repeated steroid injection in patients with hemiplegic shoulder pain and diabetes and concluded that the ideal method was to conduct three $40 \mathrm{mg}$ triamcinolone injections at one-week intervals. Considering both stability and efficacy, this study therefore used three $40 \mathrm{mg}$ triamcinolone injections administered at one-week intervals for our control group. However, there has been concern about potential degeneration changes or adverse metabolism and endocrine system events caused by high-dose steroids, ${ }^{2,6}$ which has led to new methods being developed that substitute steroids with hyaluronic acid or combine them with an adjuvant. ${ }^{7-9}$ This study conducted combination therapy using steroids and hyaluronidase, which is known to be an effective combination when used as a spinal root injection or for patients with adhesive capsulitis or peri-articular shoulder disorder, when compared to using steroid monotherapy. This study therefore aimed to examine whether or not the effect of hyaluronidase as an adjuvant increased when decreasing the number of steroid injections or whether there were adverse events caused by the injections..$^{10-13}$

Hyaluronidase, which is a mammalian water-soluble enzyme secreted by the testis or the intestinal canal, hydrolyzes the glucosamic bond between hyaluronic acid and connective tissues so as to remove the interstitial barrier, thereby modifying the permeability of connective tissues and reducing the viscosity of intercellular interaction. ${ }^{18}$ As an absorption enhancer, it is subcutaneously injected into tissues with edema so that it relieves swelling and edema. Alternatively, it can be injected together with local anesthesia or steroids to increase permeability, and is therefore widely used in ophthalmology, gynecology and anesthesiology. ${ }^{19,20}$ Seo et al. ${ }^{13}$ injected hyaluronidase and steroids into 
the articular cavity in patients with adhesive capsulitis, comparing this to steroid monotherapy. They reported that there was no significant difference in VAS scores two weeks after injection, but that there were statistically significant improvement in abduction and external rotation among passive shoulder ROM. The current study differed in its subjects and methods compared to this study, because its focus was on patients with periarticular shoulder disorder and because it examined subacromial bursa injections. In addition, our study used 3 consecutive injections at 1 -week intervals. However, in this study, no significant difference in VAS was also observed between the two groups; however, combination therapy did show statistically significant improvement of internal rotation measured by the shoulder function scale and active shoulder ROM than did the monotherapy. This suggests that hyaluronidase combined with steroids increases capillary permeability, which in turn facilitates the absorption of bursa fluid in subacromial bursitis and enhances the permeability of steroids into rotator cuff lesions in order to suppress the inflammation of the tendon around the lesion.

Between the second and third injections, both groups presented no statistically significant improvements in their VAS, on the shoulder function scale or in terms of their active ROM. When deciding on the appropriate number of steroid injections, further studies that observe various diseases and have a larger sample will be necessary. However, according to our results, patients with peri-articular shoulder disorder will benefit most from subacromial bursa injections of $40 \mathrm{mg}$ triamcinolone administered two times.

As we studied patients with peri-articular shoulder disorder, we excluded patients with a capsular pattern. It is, however, difficult to identify early adhesive capsulitis because it is similar to shoulder impingement syndrome. Therefore, this study might be limited because it did not completely exclude patients who had early adhesive capsulitis. On the other hand, we selected patients who had definite lesions shown by ultrasonic findings and who experienced stiffness; these measures should have meant that patients with early adhesive capsulitis were likely to be excluded. Recently, methods for distinguishing early adhesive capsulitis through ultrasonographic testing have been developed, ${ }^{21,22}$ which may be useful for further studies such as ours when selecting eligible subjects. Another limitation may be that long-term effect of combination therapy is not clear due to our small sample size and short follow-up period. Therefore, further study in this area should have a larger sample size and extend the follow-up period.

\section{CONCLUSION}

Subacromial bursa injections of steroids (40 mg triamcinolone) and hyaluronidase in patients with periarticular shoulder disorder may have an additive effect in causing improvement of internal rotation active ROM and improving shoulder joint function.

\section{REFERENCES}

1. Kim SB, Yoon K, Park HS, Kwak H, Ha NJ, Park JS, Gu BS. Ultrasonography in the shoulder impingement syndrome. J Korean Acad Rehab Med 2000; 24: 542550

2. Yoon SH, Kwack KS, Rah UW, Cho KH. Ultrasonography-guided subacromial bursal injection of corticosteroid: a comparative study of two dose regimens. J Korean Acad Rehab Med 2009; 33: 402-407

3. Naredo E, Cabero F, Beneyto P, Cruz A, Monderjar B, Uson J, Palop MG, Crespo M. A randomized comparative study of short term response to blind injection versus sonographic guided injection of local corticosteroids in patients with painful shoulder. J Rheumatol 2004; 31: 308-314

4. Chen MJ, Lew HL, Hsu TC, Tsai WC, Lin WC, Tang SF, Lee YC, Hsu RC, Chen CP. Ultrasound-guided shoulder injections in the treatment of subacromial bursitis. Am J Phys Med Rehabil 2006; 85: 31-35

5. Blair B, Rokito AS, Cuomo F, Jarolem K, Zuckerman JD. Efficacy of injections of corticosteroids for subacromial impingement syndrome. J Bone Joint Surg Am 1996; 78: 1685-1689

6. Byun SD, Park DH, Jo DH, Choi WD, Lee ZI. Effect of three consecutive steroid injection on blood glucose and cortisol level in diabetic patients with hemiplegic shoulder pain. J Korean Assoc Pain Med 2010; 9: 82-89

7. van Den Ende CH, Rozing PM, Dijkmans BA, Verhoef JA, Voogt-van der Harst EM, Hazes JM. Assessment of shoulder function in rheumatoid arthritis. J Rheumatol 1996; 23: 2043-2048 
8. Kim C, Park YB, Youn JE, Kim DY. Treatment of adhesive capsulitis with steroid injection followed by hyaluronic acid injection. J Korean Acad Rehab Med 2010; 34: 310-315

9. Chou WY, Ko JY, Wang FS, Huang CC, Wong T, Wang $\mathrm{CJ}$, Chang HE. Effect of sodium hyaluronate treatment on rotator cuff lesions without complete tears: a randomized, double-blind, placebo-controlled study. J Shoulder Elbow Surg 2010; 19: 557-563

10. Gourie-Devi M, Satishchandra P. Hyaluronidase as an adjuvant in the management of tuberculous spinal arachnoiditis. J Neurol Sci 1991; 102: 105-111

11. Lee KJ, Han SG, Yoon SH, Kim JS, Lee YS. Nerve root block with corticosteroids, hyaluronidase and local anesthetic in the failed back surgery syndrome (FBSS). J Korean Assoc Pain Med 1999; 12: 191-194

12. Devulder J. Transforaminal nerve root sleeve injection with corticosteroids, hyaluronidase and local anesthetic in the failed back surgery syndrome. J Spinal Disord 1998; 11: 151-154

13. Seo JH, Lee RJ, Park SH, Na SY, Ko MH. The effect of intraarticular injection of hyaluronidase in patients with adhesive capsulitis of shoulder. J Korean Assoc Pain Med 2006; 5: 122-127

14. Croft P, Pope D, Zonca M, O`Neill T, Silman A. Measurement of shoulder related disability: results of a validation study. Ann Rheum Dis 1994; 53: 525-528

15. Cho KH, Gee SJ, Lee HJ, Hwang SH. Comparison of blind technique and ultrasonography guided technique of subacromial subdeltoid bursa injection. J
Korean Acad Rehab Med 2010; 34: 209-213

16. Tillander B, Franzen LE, Karlsson MH, Norlin R. Effect of steroid injections on the rotator cuff: an experimental study in rats. J Shoulder Elbow Surg 1999; 8: 271-274

17. Akpinar S, Hersekli MA, Demirors H, Tandogan RN, Kayaselcuk F. Effects of methylprednisolone and betamethasone injections on the rotator cuff: an experimental study in rats. Adv Ther 2002; 19: 194-201

18. Menzel EJ, Farr C. Hyaluronidase and its substrate hyaluronan: biochemistry, biological activities and therapeutic uses. Cancer Lett 1998; 131: 3-11

19. Remy M, Pinter F, Nentwich MM, Kampik A, Schönfeld CL. Efficacy and safety of hyaluronidase $75 \mathrm{IU}$ as an adjuvant to mepivacaine for retrobulbar anesthesia in cataract surgery. J Cataract Refract Surg 2008; 34: 1966-1969

20. Doumouchtsis SK, Boama V, Gorti M, Tosson S, Fynes MM. Prospective evaluation of combined local bupivacaine and steroid injections for the management of chronic vaginal and perineal pain. Arch Gynecol Obstet 2011; 284: 681-685

21. Kwon DR, Kim MY, Chae YJ, Park JS, Kim JS, Yi TI. Comparison of coracohumeral ligment thickness between asymptomatic shoulders and adhesive capsulitis in Korean. J Korean Acad Rehab Med 2009; 33: 392-395

22. Kang TD, Hwang DH, Jung KI, Park DS, Jang KE. Ultrasonography in adhesive capsulitis of shoulder. J Korean Acad Rehab Med 1998; 22: 944-949 